\title{
A Model for the Identification of Bacteria
}

\author{
By E. W. RYPKA, W. E. CLAPPER, I. G. BOWEN \\ AND R. BABB \\ Department of Microbiology and Department of Physics, \\ Lovelace Foundation for Medical Education and Research, \\ Albuquerque, New Mexico 87108, U.S.A.
}

(Accepted for publication 18 October 1966)

\begin{abstract}
SUMMARY
Two methods are described for determining the shortest route to an identification. The methods are based upon the reduction to a minimum test set, as suggested by Gyllenberg (1963), which will result in the most efficient separation of the organisms. The first method is used when no test results for characters are considered variable; the second method is applicable when some characters are variable and others are not. To illustrate the methods two sets of data are reduced. One set includes the reduction to a minimum set of 6 tests from 32 tests for 36 organisms in the Enterobacteriaceae. The other set includes the reduction to a minimum set of 3 tests from 34 tests for 8 Pasteurella species. The methods described may be used manually or be programmed for a computer.
\end{abstract}

\section{INTRODUCTION}

For the efficient identification of large numbers of organisms, it would be desirable to know which set of tests would be most effective in separating a group of organisms into progressively smaller subgroups with equal, or nearly equal, numbers of organisms. The number of subgroups ideally would equal the original number of organisms. If this situation could be attained, there would be complete separation of the organisms in a group. If only one organism were separated into a subgroup, this would constitute an identification. In addition, a minimal number of tests would have been done in order to effect separation, that is, the shortest route to an identification would have been used. Gyllenberg $(1963,1964)$ has given consideration to a general method of determining the 'minimum set' of tests required for separation of groups of organisms. His methods, with some modification, have been applied to representative species in the Enterobacteriaceae to develop a generalized programme for the Burroughs 5500 Computer.

\section{METHODS}

An idealized example. The number of tests required for the minimum set is determined by the number of organisms to be separated. Considering only two-state tests, that is, tests for characters that may be recorded as present $(+$ or 1$)$ or absent $(-$ or 0$)$, two organisms may be separated by one test, three to four organisms would require a minimum of two tests, five to eight organisms three tests, nine to sixteen organisms four tests, etc. These are idealized circumstances. According to Gyllenberg (1963), the minimum set of tests is $T_{\mathrm{min}}=\log _{2} G$, or in exponential notation, $2^{\boldsymbol{T}}=G$, where 
$T$ is the number of tests in the minimum set and $G$ the number of organisms in the group.

The idealized situation is illustrated in Table 1. In the three examples in this table each test has an equal number of 1 and 0 results although the alternating sequence of 1 's and 0 's varies. Thus, for the most efficient separation of organisms each test in the minimum set would have an equal number of alternating sequences of 1 and 0 test results. The proper number of alternating sequences of 1 and 0 test results, where $N$ the number of organisms is even, would be $N / 2, N / 4, \ldots, N / N$. For example, with 8 organisms and 3 tests, $8 / 2=4,8 / 4=2$, and $8 / 8=1$. In the third example in Table 1 , test 1 (four 1's and four 0's) separates the organisms into 2 subgroups each with 4 organisms. Test 2 (alternating two 1's and two 0's) separates the 2 subgroups into 4 subgroups each with 2 organisms. Test 3 (alternating 1's and 0's) separates the 4 subgroups into 8 subgroups each with 1 organism.

Table 1. Idealized separation of organisms into subgroups

Organisms Tests and results

One test separates 2 organisms*

Test 1

$\begin{array}{ll}A & 1(\text { or }+) \\ B & 0(\text { or }-)\end{array}$

$\begin{array}{ccc} & \text { Two tests separate } 3 \text { to } \\ & \text { Test } 1 & \text { Test } 2 \\ A & 1 & 1 \\ B & 1 & 0 \\ C & 0 & 1 \\ D & 0 & 0\end{array}$

\begin{tabular}{lccc} 
& \multicolumn{3}{c}{ Three tests separate 5 to 8 organisms* } \\
& Test 1 & Test 2 & Test 3 \\
$A$ & 1 & 1 & 1 \\
$B$ & 1 & 1 & 0 \\
$C$ & 1 & 0 & 1 \\
$D$ & 1 & 0 & 0 \\
$E$ & 0 & 1 & 1 \\
$F$ & 0 & 1 & 0 \\
$G$ & 0 & 0 & 1 \\
$H$ & 0 & 0 & 0 \\
$N=8$ & $8 / 2=4$ & $8 / 4=2$ & $8 / 8=1$
\end{tabular}

* One two-state test has 2 possible results, 1 (or + ) and 0 (or-). Two two-state tests have 4 possible results, 11 (or ++ ), 10 (or +- ), 01 (or -+ ), and 00 (or -- ), or in general the number of possible unique combinations for two-state tests is $2^{T}$ where $T$ is the number of tests.

It will be noticed in the last example in Table 1 that each of the 3 tests results in the same number of separations. Test 1 for organism $A$ is 1 , and this separates $A$ from organisms $E, F, G$, and $H$ which are 0 for this test. Hence, there are 4 separations. The same applies to organisms $B, C$ and $D$ which are 1 for the first test and organisms $E$, $F, G$, and $H$ which are 0 . There are a total of 16 separations effected by test 1 . This procedure is applicable in a similar manner for tests 2 and 3 each of which results in 16 separations.

The same result is obtained if the number of 1's $\left(n_{1}\right)$ and the number of 0 's $\left(n_{0}\right)$ for 
each test are multiplied together, that is, $n_{1} n_{0}$. This is the 'separation figure $(S)$ ' of Gyllenberg (1963), $S=U V$ or $S=n_{1} n_{0}$. If the tests for the organisms in a group are analysed by this method, that test with the highest $S$ value will be the first best test. It usually will separate the organisms into two subgroups with an equal, or nearly equal, number of organisms. The application of Gyllenberg's formula is not limited necessarily to one test, that is, it may be used to calculate the $S$ value for two or more tests. A generalized equation, applicable when no test results are variable, has been derived by I. G. Bowen. The term 'combination' as used in this derivation refers to the possible unique combinations of 1's and of 0 's when all of the tests $(T)$ in the minimum set are considered variable $(v)$. Thus, if there were 5 tests there would be $2^{T_{v}}=2^{5}=32$ possible unique combinations. Examples of these combinations are given in Table 1 and at the bottom of Tables 3, 4, 9, 12, and 14. Let

$$
\begin{aligned}
& N=\text { total number of organisms, } \\
& n_{a}=\text { total number of organisms with combination } a, \\
& n_{b}=\text { total number of organisms with combination } b, \\
& n_{i}=\text { total number of organisms with combination } i .
\end{aligned}
$$

Then, $\left(N-n_{a}\right)$ is the number of organisms not having combination ' $a$ ' and consequently is the number of separations for each ' $a$ ' organism. For $n_{a}$ organisms, the separations would be $n_{a}\left(N-n_{a}\right)$. Similar expressions can be written for organisms with combinations ' $b$ '...' $i$ '; however, in arriving at the total number of separations it should be remembered that each separation has been counted twice. Thus, the total separations, $S$, is given by

which reduces to

$$
S=\frac{1}{2}\left[n_{a}\left(N-n_{a}\right)+n_{b}\left(N-n_{b}\right)+\ldots+n_{i}\left(N-n_{i}\right)\right]
$$

$$
S=\frac{1}{2}\left[N^{2}-\left(n_{a}^{2}+n_{b}^{2}+\ldots+n_{i}^{2}\right)\right]
$$

The application of this equation is illustrated next.

When no characters are considered variable. If one is dealing with a large number of organisms to be identified, it usually is impossible to find a sufficient number of characters for the determinative scheme that, as far as the available data indicate, are not variable. That is, few characters are definitely always present or always absent. A character that is variable is useful for a determinative scheme if the frequency it is present or absent is known. Cowan \& Steel (1965), in their diagnostic tables, state that a positive or negative test result for a character means $80-100 \%$ positive or negative and $0-20 \%$ negative or positive, respectively. The procedures to be discussed are applicable to finding the minimum set of tests for separation of a group of organisms when no characters are variable or when confidence levels for the relative frequency that variable characters are positive or negative have been established. Gyllenberg (1963) has given consideration to these procedures.

Hypothetical data are given in Table 2 for 8 organisms and 5 tests. The left part of the table gives the data for the test results of the organisms and the $S$ values for the tests. The right side of the table shows the tests arranged in descending order of their $S$ values. Ideally 3 two-state tests $\left(2^{3}=8\right)$ would be required to separate the 8 organisms as illustrated in Table 1. The problem is to find the combination of 3 of the 5 tests that will result in the most efficient separation of the 8 organisms. For illustrative purposes we shall find the first 2 tests and then the first 3 . It should be emphasized, however, that we could directly find the first 3 tests. 
One two-state test could separate 2 or more organisms into 2 subgroups, those organisms that were 1 for the test and those organisms that were 0 . As indicated in Table 2, test 4 gives the largest number of separations for one test. Two two-state tests could separate the organisms into subgroups with the following possible unique combinations of test results, 11, 10, 01, 00 (or,,,+++--+-- ). First it is desired to

Table 2. Hypothetical data for organisms and their test results. The $S$ values are calculated for each test and the tests are rearranged in descending order of their $S$ values in the right part of the table

\begin{tabular}{|c|c|c|c|c|c|c|c|c|c|c|c|}
\hline \multirow[b]{2}{*}{ Organisms } & \multicolumn{5}{|c|}{ Tests } & & \multicolumn{5}{|c|}{ Tests } \\
\hline & 1 & 2 & 3 & 4 & 5 & Organisms & 4 & 2 & 1 & 3 & 5 \\
\hline 1 & 0 & 1 & 0 & 1 & 1 & 1 & 1 & 1 & 0 & 0 & 1 \\
\hline 2 & 0 & 0 & 0 & 1 & 1 & 2 & 1 & 0 & 0 & 0 & 1 \\
\hline 3 & 0 & 1 & 1 & 1 & 1 & 3 & 1 & 1 & 0 & 1 & 1 \\
\hline 4 & 0 & 0 & 0 & 0 & 1 & 4 & 0 & 0 & 0 & 0 & 1 \\
\hline 5 & 1 & 1 & 0 & 0 & 0 & 5 & 0 & 1 & 1 & 0 & 0 \\
\hline 6 & 0 & 1 & 0 & 0 & 1 & 6 & 0 & 1 & 0 & 0 & 1 \\
\hline 7 & 1 & 1 & 0 & 0 & 1 & 7 & 0 & 1 & 1 & 0 & 1 \\
\hline 8 & 0 & 0 & 1 & 1 & 0 & 8 & 1 & 0 & 0 & 1 & 0 \\
\hline$n_{1}$ & 2 & 5 & 2 & 4 & 6 & Tests arran & $\mathrm{d}$ in & decer & ding & rder & \\
\hline$n_{n}$ & 6 & 3 & 6 & 4 & 2 & $S$ values & & & & & \\
\hline$S^{*}=$ & 12 & 15 & 12 & 16 & 12 & & 16 & 15 & 12 & 12 & 12 \\
\hline
\end{tabular}

find that combination of 2 tests which most closely would approach the ideal condition of separating 8 organisms into 4 subgroups each with 2 organisms. To determine this it only is necessary to find the number of combinations $(C)$ of 5 tests taken 2 at a time, or

$$
C_{2}^{5}=\frac{5(5-1)}{2 !}=\frac{5 \cdot 4}{1 \cdot 2}=10 \text {. }
$$

Next a count is made of the number of organisms which are separated into the 4 possible unique combinations of results for 2 two-state tests. This is illustrated in Table 3. Of the 10 possible combinations of 5 tests taken 2 at a time, tests 4 and 2 appear to approach most closely the ideal separation.

This same result could be obtained by using equation (1) in the form

$$
S=\frac{1}{2}\left[N^{2}-\left(n_{11}^{2}+n_{10}^{2}+n_{01}^{2}+n_{00}^{2}\right)\right],
$$

where again $N$ is the number of organisms in the group and $n_{11}, n_{10}, n_{01}$, and $n_{00}$ are the number of organisms with the 4 possible unique combinations of 2 two-state tests. $S$ will approach a maximum value when $n_{11}, n_{10}, n_{01}$, and $n_{00}$ each approach $N / 4$ as a limit. That is, when $N / 4=8 / 4=2=n_{11}=n_{10}=n_{01}=n_{00}$, the maximum value for $S$ is 24 . The $S$ value for the 10 combinations of 2 two-state tests are given at the bottom of Table 3 . The test combination 4-2 most closely approaches the ideal separation $(S=24)$ with a value of 23 and these 2 tests are selected for the first 2 best tests.

This process is repeated again to find the 3 first best tests. In this case, however, equation (1) becomes

$$
S=\frac{1}{2}\left[N^{2}-\left(n_{111}^{2}+n_{110}^{2}+n_{101}^{2}+n_{100}^{2}+n_{011}^{2}+n_{010}^{2}+n_{001}^{2}+n_{000}^{2}\right)\right]
$$


and the maximum value for $S$ will be obtained when each $n$ approaches $N / 8$ as a limit. This value is 28 . The possible combinations of 5 tests taken 3 at a time are 10 .

$$
C_{3}^{5}=\frac{5 \cdot 4 \cdot 3}{3 !}=10
$$

Table 3. Possible combinations of 5 tests taken 2 at a time (from Table 2) and the number of organisms that are separated into each unique combination of 2 two-state tests

\begin{tabular}{|c|c|c|c|c|c|c|c|c|c|c|c|c|c|c|c|c|c|c|c|c|}
\hline \multirow[b]{2}{*}{ Organism } & \multicolumn{20}{|c|}{ Combination of tests } \\
\hline & 4 & 2 & 4 & 1 & 4 & 3 & 4 & 5 & 2 & 1 & 2 & 3 & 2 & 5 & 1 & 3 & 1 & 5 & 3 & 5 \\
\hline 1 & 1 & 1 & 1 & 0 & 1 & 0 & 1 & 1 & 1 & 0 & 1 & 0 & 1 & 1 & 0 & 0 & 0 & 1 & $\mathbf{0}$ & \\
\hline 2 & 1 & 0 & 1 & 0 & 1 & $\mathbf{0}$ & 1 & 1 & 0 & 0 & 0 & 0 & 0 & 1 & 0 & 0 & 0 & 1 & 0 & 1 \\
\hline 3 & 1 & 1 & 1 & 0 & 1 & 1 & 1 & 1 & 1 & 0 & 1 & 1 & 1 & 1 & 0 & 1 & 0 & 1 & 1 & \\
\hline 4 & 0 & 0 & 0 & 0 & 0 & 0 & 0 & 1 & 0 & 0 & 0 & 0 & 0 & 1 & 0 & 0 & 0 & 1 & 0 & \\
\hline 5 & 0 & 1 & 0 & 1 & 0 & 0 & 0 & 0 & 1 & 1 & 1 & 0 & 1 & 0 & 1 & 0 & 1 & 0 & 0 & \\
\hline 6 & 0 & 1 & 0 & 0 & 0 & 0 & 0 & 1 & 1 & 0 & 1 & 0 & 1 & 1 & 0 & 0 & 0 & 1 & 0 & \\
\hline 7 & 0 & 1 & 0 & 1 & 0 & 0 & 0 & 1 & 1 & 1 & 1 & 0 & 1 & 1 & 1 & 0 & 1 & 1 & 0 & \\
\hline 8 & 1 & 0 & 1 & 0 & 1 & 1 & 1 & 0 & 0 & 0 & 0 & 1 & 0 & 0 & 0 & 1 & 0 & 0 & 1 & \\
\hline
\end{tabular}

Number of organisms in each unique combination of 2 two-state tests

$\begin{array}{crrrrrrrrrr}\text { Combination } & n & n & n & n & n & n & n & n & n & n \\ 11 & 2 & 0 & 2 & 3 & 2 & 1 & 4 & 0 & 1 & 1 \\ 10 & 2 & 4 & 2 & 1 & 3 & 4 & 1 & 2 & 1 & 1 \\ 01 & 3 & 2 & 0 & 3 & 0 & 1 & 2 & 2 & 5 & 5 \\ 00 & 1 & 2 & 4 & 1 & 3 & 2 & 1 & 4 & 1 & 1 \\ S^{*} & 23 & 20 & 20 & 22 & 21 & 21 & 21 & 20 & 18 & 18 \\ & \end{array}$

Table 4. Possible combinations of 5 tests taken 3 at a time (from Table 2) and the number of organisms that are separated into each unique combination of 2 two-state tests

Combination of tests

\begin{tabular}{clllllllllllllllllllllllllllllllll} 
Organism & \multicolumn{1}{c}{} & 2 & 1 & 4 & 2 & 3 & 4 & 2 & 5 & 4 & 1 & 3 & 4 & 1 & 5 & 4 & 3 & 5 & 2 & 1 & 3 & 2 & 1 & 5 & 2 & 3 & 5 & 1 & 3 & 5 \\
1 & 1 & 1 & 0 & 1 & 1 & 0 & 1 & 1 & 1 & 1 & 0 & 0 & 1 & 0 & 1 & 1 & 0 & 1 & 1 & 0 & 0 & 1 & 0 & 1 & 1 & 0 & 1 & 0 & 0 & 1 \\
2 & 1 & 0 & 0 & 1 & 0 & 0 & 1 & 0 & 1 & 1 & 0 & 0 & 1 & 0 & 1 & 1 & 0 & 1 & 0 & 0 & 0 & 0 & 0 & 1 & 0 & 0 & 1 & 0 & 0 & 1 \\
3 & 1 & 1 & 0 & 1 & 1 & 1 & 1 & 1 & 1 & 1 & 0 & 1 & 1 & 0 & 1 & 1 & 1 & 1 & 1 & 0 & 1 & 1 & 0 & 1 & 1 & 1 & 1 & 0 & 1 & 1 \\
4 & 0 & 0 & 0 & 0 & 0 & 0 & 0 & 0 & 1 & 0 & 0 & 0 & 0 & 0 & 1 & 0 & 0 & 1 & 0 & 0 & 0 & 0 & 0 & 1 & 0 & 0 & 1 & 0 & 0 & 1 \\
5 & 0 & 1 & 1 & 0 & 1 & 0 & 0 & 1 & 0 & 0 & 1 & 0 & 0 & 1 & 0 & 0 & 0 & 0 & 1 & 1 & 0 & 1 & 1 & 0 & 1 & 0 & 0 & 1 & 0 & 0 \\
6 & 0 & 1 & 0 & 0 & 1 & 0 & 0 & 1 & 1 & 0 & 0 & 0 & 0 & 0 & 1 & 0 & 0 & 1 & 1 & 0 & 0 & 1 & 0 & 1 & 1 & 0 & 1 & 0 & 0 & 1 \\
7 & 0 & 1 & 1 & 0 & 1 & 0 & 0 & 1 & 1 & 0 & 1 & 0 & 0 & 1 & 1 & 0 & 0 & 1 & 1 & 1 & 0 & 1 & 1 & 1 & 1 & 0 & 1 & 1 & 0 & 1 \\
8 & 1 & 0 & 0 & 1 & 0 & 1 & 1 & 0 & 0 & 1 & 0 & 1 & 1 & 0 & 0 & 1 & 1 & 0 & 0 & 0 & 1 & 0 & 0 & 0 & 0 & 1 & 0 & 0 & 1 & 0
\end{tabular}

Number of organisms in each unique combination of 3 two-state tests

$\begin{array}{crrrrrrrrrr}\text { Combination } & n & n & n & n & n & n & n & n & n & n \\ 111 & 0 & 1 & 2 & 0 & 0 & 1 & 0 & 1 & 1 & 0 \\ 110 & 2 & 1 & 0 & 0 & 0 & 1 & 2 & 1 & 0 & 0 \\ 101 & 0 & 1 & 1 & 2 & 3 & 2 & 1 & 3 & 3 & 1 \\ 100 & 2 & 1 & 1 & 2 & 1 & 0 & 2 & 0 & 1 & 1 \\ 011 & 2 & 0 & 2 & 0 & 1 & 0 & 0 & 0 & 0 & 1 \\ 010 & 1 & 3 & 1 & 2 & 1 & 0 & 0 & 0 & 1 & 1 \\ 001 & 0 & 0 & 1 & 0 & 2 & 3 & 1 & 2 & 2 & 4 \\ 000 & 1 & 1 & 0 & 2 & 0 & 1 & 2 & 1 & 0 & 0 \\ S^{*}= & 25 & 25 & 26 & 24 & 24 & 24 & 25 & 24 & 24 & 22\end{array}$

* $S=\frac{1}{2}\left[N^{2}-\left(n_{111}^{2}+n_{110}^{2}+n_{101}^{2}+n_{100}^{2}+n_{011}^{2}+n_{010}^{2}+n_{001}^{2}+n_{000}^{2}\right)\right]$. 
The reduction of data for finding the 3 first best tests is presented in Table 4 . The highest $S$ value is 26 for the combination of tests 4,2 and 5, and these tests are selected for the first 3 which effect maximum separation.

Gyllenberg (1964) used organism versus organism matrices to determine the completeness of the test set. A test that separates 2 organisms is entered into the proper space of the matrix (a 'point of separation') and when all parts of the matrix are filled, the test set is complete and all organisms may be separated. The number of spaces to be filled in the matrix is $t(t-1) / 2(t=$ number of organisms) or these are the number of spaces to be filled below the diagonal line in Table 5. The top right-hand side of the table is not filled-in because it is a mirror image of the bottom left-hand side of the table. There are 28 spaces $(t(t-1) / 2=8(8-1) / 2=28)$ to be filled-in. This is the same answer given by equation (1) for the ideal conditions that 3 tests would separate completely 8 organisms. Gyllenberg's (1964) method, $t(t-1) / 2$, is less cumbersome.

Table 5. An organism versus organism matrix in which the test number* that results in a separation of 2 organisms is recorded in the appropriate square

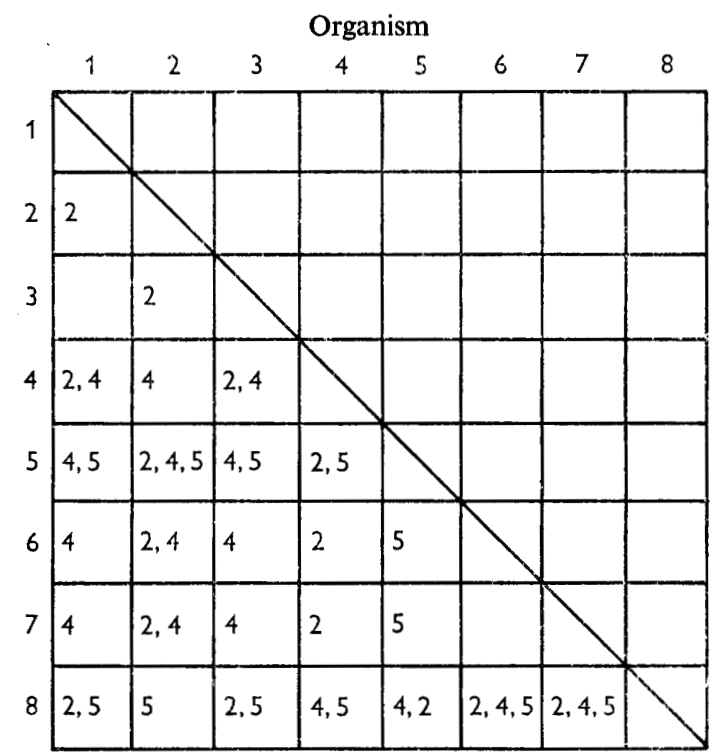

* Test numbers refer to test combination 4,2 , and 5 which has an $S$ value of 26 . This value agrees with the number of spaces filled in the matrix above. See Table 4.

However, equation (1) can be used directly to determine the number of spaces that have been filled by the selection of the first, second, third,..., etc., tests-and this obviates the use of matrix analysis. By counting the spaces in Table 5 occupied by tests 2, 4, and 5, or any combination of these tests, it can be determined that the number of spaces occupied in the matrix agrees with the answers obtained by using equation (1). When two or three of the tests occur together in the same space in the matrix they are counted only once.

Equation (1) also may be used if test results are variable but in this case the entire table of organisms and their test results must be expanded first to indicate the possible 
unique combinations. For example, if organism $A$ is variable (v or 2 ) for two of five tests there are 4 possible combinations of results for 2 two-state tests. The expansion of the results for organism $A$ would be as follows:

\begin{tabular}{cccccc} 
& \multicolumn{5}{c}{ Tests } \\
Organism & 1 & 2 & 3 & 4 & 5 \\
$A$ & 1 & 2 & 0 & 1 & 2 \\
$A_{1}$ & 1 & 1 & 0 & 1 & 1 \\
$A_{2}$ & 1 & 1 & 0 & 1 & 0 \\
$A_{3}$ & 1 & 0 & 0 & 1 & 1 \\
$A_{4}$ & 1 & 0 & 0 & 1 & 0
\end{tabular}

Tests 2 and 5 are variable and there are 4 possible combinations $\left(2^{T_{v}}=2^{2}=4\right)$ for 2 variable tests, $11,10,01$, and 00 . Test 2 , for the 4 possible combinations is written in the sequence: $1,1,0,0$, and test $5: 1,0,1,0$. This gives 4 unique combinations of results for organism $A$.

If equation (1) is used to determine the first test by this method the most variable test, in general, will be selected because the number of 1 and of 0 reactions would be about equal after expansion of the table. In addition, the method is not efficient when a large number of variable characters occur. If 30 characters for an organism were being considered, and 10 of the characters were variable, the expansion of the table for this organism would be $2^{T_{v}}=2^{10}=1024$. In actual practice this situation frequently arises because of lack of information. Characters for which no data are available are considered variable on the assumption that the character must be either present or absent.

When some tests are considered variable. In the diagnostic laboratory or when bacterial flora studies are undertaken and it is not known on the basis of previous experience what organisms may be identified, the study will only be as comprehensive as the primary environmental conditions used for isolation and the inclusiveness of the keys to be used for identification. This situation is complicated further because classifications into which organisms are to be identified are dynamic and not static. That is, as more information becomes available justification can be found for reclassification. This, in a sense, also reveals the dynamic state of bacterial populations.

Ideally, in either case, that of the diagnostic laboratory or larger bacterial flora studies, the keys constructed for identification should be as inclusive as possible. If this is done the concept of the minimum test set of Gyllenberg (1963) becomes important particularly in regard to the volume of work and the time required for inoculation of media and reading of tests. That is, unless a laboratory has unlimited resources of time and personnel the shortest route to an identification must be taken.

A separate table is used to collect data for each organism to be considered. The data for all organisms then are compiled into one large table and from this the minimum set of tests required for maximum separation of the organisms is determined. In constructing tables of organisms and their test results it is necessary to decide what constitutes a positive reaction, a negative reaction, and a variable reaction. This may vary depending upon the findings of different investigators. A very rough approximation was made by analysing the results of each test for a species as designated by various investigators, and the test results were divided into 4 approximate confidence levels, 99, 95, 90, and $80 \%$. This is illustrated in Table 6 for Escherichia coli. 
All references agree mannitol fermentation is positive $99 \%$ or more of the time and this is recorded positive at all 4 confidence levels. Lactose fermentation is considered positive by 4 references, $90.5 \%$ positive and $5.5 \%$ delayed positive by Edwards \& Ewing (1964), and $92 \%$ positive by Møller (1954). Lactose fermentation is summarized variable at the 99 and $95 \%$ confidence levels and positive at 90 and $80 \%$. In general, delayed positive reactions are considered negative and for this reason citrate utilization is summarized as negative at all four confidence levels. Qualitative data for variable reactions such as that found in Bergey's Manual (1957) arbitrarily were given precedence over quantitative data and the summary for the reaction would be considered variable. This approach is biased and allows for more variation and fewer separations. However, on the basis of the minimum test set it is desired to include, and not exclude, as many organisms as possible. Quantitative data using the same standardized test procedures will be required before significant results can be obtained for variable reactions.

Table 6. Approximating confidence levels of test results for Escherichia coli

\begin{tabular}{|c|c|c|c|}
\hline \multirow[b]{2}{*}{ Source* } & \multicolumn{3}{|c|}{ Tests } \\
\hline & Mannitol & Lactose & Citrate \\
\hline $\begin{array}{l}a \\
b\end{array}$ & $\begin{array}{c}+ \\
+>99 \%\end{array}$ & $\stackrel{+}{+}+90.5 \%(5.5 \%) \dagger$ & $+0.3 \%(0.8 \%) \dagger$ \\
\hline$c$ & + & + & + \\
\hline$d$ & + & + & - \\
\hline$e$ & + & $+92 \%$ & $-9 x+$ \\
\hline \multirow[t]{6}{*}{$f$} & + & + & - \\
\hline & \multicolumn{3}{|c|}{ Estimate of confidence level } \\
\hline & $99 \%$ & + & - \\
\hline & $95 \%$ & $v$ & - \\
\hline & $90 \%$ & + & - \\
\hline & $80 \% \S$ & + & - \\
\hline
\end{tabular}

* Data from: a, Bergey's Manual (1957); b, Edwards \& Ewing (1964); c, Lysenko (1959); $d$, Cowan (1956); $e$, Møller (1954); $f$, Kauffmann (1956).

$\dagger$ Figures in parentheses represent percentage delayed positive reactions which arbitrarily are considered negative.

$\$ 91 \%$ of strains negative, $9 \%$ delayed or weakly positive.

$\S$ If data from Cowan \& Steel $(1961,1965)$ are applicable the confidence level is $80 \%$ because $a+$ or - means $80-100 \%$.

In Table 7 will be found data for ten organisms in the Enterobacteriaceae. The confidence level is approximately $80 \%$. Two different procedures may be used to determine if sufficient tests are included to give complete separation of the organisms in the group. The test results for each organism may be compared with those of each other organism. The results for organism 1 are compared with those of organisms 2, 3, 4 , etc., and whenever a $1-0$ or $0-1$ combination occurs there is separation. If no 1-0 or 0-1 combination occurs the organisms cannot be separated. Next, results for organism 2 are compared against organisms $3,4,5$, etc., and this process is continued until all comparisons are made. When this is completed it is found that organisms 1,2 , 4,8 , and 10 are separated, and that the following organisms are not separated, 3 from 7, 5 from 7 and 9, 6 from 7, and 7 from 9. The data in Table 7 also may be used 
as input for the computer and the output is a listing of the organisms separated and the tests required for separation. The organisms not separated are not listed.

From this type of analysis, either manual or automatic, it is known that the test set is incomplete and not all the organisms are separated as single answers. To keep the illustration within bounds, however, these data will be used to determine which minimum set of tests will result in the most efficient separation of the organisms.

Table 7. Test results* for 10 organisms in the enterobacteriaceae

\begin{tabular}{|c|c|c|c|c|c|c|c|c|c|}
\hline \multirow[b]{2}{*}{ No. } & \multirow[b]{2}{*}{ Organisms } & \multicolumn{8}{|c|}{ Tests } \\
\hline & & $\begin{array}{c}1 \\
\text { LD }\end{array}$ & $\stackrel{2}{\mathrm{KCN}}$ & $\begin{array}{c}3 \\
\mathrm{H}_{2} \mathrm{~S}\end{array}$ & $\stackrel{4}{\mathrm{LAC}}$ & $\begin{array}{c}5 \\
\mathrm{OD}\end{array}$ & $\stackrel{6}{\text { ARAB }}$ & $\begin{array}{c}7 \\
\text { INOS }\end{array}$ & $\begin{array}{c}8 \\
\text { CIT }\end{array}$ \\
\hline 1 & Escherichia coli & 2 & 0 & 0 & 1 & 2 & 1 & 0 & 0 \\
\hline 2 & E. freundii & 0 & 1 & 1 & 1 & 2 & 1 & 2 & 2 \\
\hline 3 & Aerobacter aerogenes & 1 & 1 & 0 & 1 & 1 & 1 & 1 & 2 \\
\hline 4 & A. cloacae & 0 & 1 & 0 & 1 & 2 & 1 & 0 & 2 \\
\hline 5 & Klebsiella pneumoniae & 1 & 2 & 0 & 2 & 0 & 1 & 2 & 1 \\
\hline 6 & Arizona group & 1 & 0 & 1 & 2 & 1 & 1 & 0 & 2 \\
\hline 7 & Serratia & 1 & 2 & 2 & 2 & 2 & 2 & 2 & 1 \\
\hline 8 & Proteus vulgaris & 0 & 1 & 1 & 0 & 0 & 0 & 0 & 2 \\
\hline 9 & Salmonella typhi & 1 & 0 & 2 & 0 & 0 & 2 & 2 & 2 \\
\hline 10 & Shigella dysenteriae & 0 & 0 & 0 & 0 & 0 & 2 & 0 & 0 \\
\hline & $n_{1}$ & 5 & 4 & 3 & 4 & 2 & 6 & 1 & 2 \\
\hline & $n_{0}$ & 4 & 4 & 5 & 3 & 4 & 1 & 5 & 2 \\
\hline & $S \dagger=$ & 20 & 16 & 15 & 12 & 8 & 6 & 5 & 4 \\
\hline
\end{tabular}

* A positive reaction (1) or negative reaction (0) means positive or negative approximately $80 \%$ of the time. Variable reactions are designated 2. LD = lysine decarboxylase, LAC = lactose, $\mathrm{OD}=$ ornithine decarboxylase, $\mathrm{ARAB}=$ arabinose, $\mathrm{INOS}=$ inositol, $\mathrm{CIT}=$ citrate.

$\dagger S=\frac{1}{2}\left[N^{2}-\left(n_{1}^{2}+n_{0}^{2}\right)\right]=n_{1} n_{0}$. Variable test results, designated 2, are not used in the calculation.

The first best test is based upon the highest $S$ value. In Table 7 the tests are arranged in descending order of their $S$ values as indicated at the bottom of the table. In calculating $S$ values, reactions which are variable, designated by 2 , are omitted and only the 1 and 0 reactions are considered. It will be noted in Table 7, in general, that the $S$ values decrease as the number of variables increases. An inversion occurs with tests 5 and 6, i.e. test 5 has 4 variables and test 6 has 3 variables and their $S$ values are 8 and 6 respectively.

To find the first 2 best tests, there are 28 possible combinations of 8 tests taken 2 at a time. However, in the automatic selection of the first 2 best tests, the computer does not make every possible combination. After the selection of the first best test, each remaining test is used with the first test and the combination that effects the largest number of separations is selected for the first 2 best tests. In this case 7 combinations of 2 tests were made, i.e. $1-2,1-3,1-4,1-5,1-6,1-7$, and 1-8. The combination of tests 1-2 and 1-3 each effect 29 separations which is the maximum separation for any 2 tests. This is illustrated in an organism versus organism matrix in Table 8 . Note there are 45 spaces in the matrix to be occupied under the diagonal line. The separation spaces $(S S)$ for any combination of 2 tests is: $S S_{\text {test }_{1}}+$ (number of times test being compared with 1 occurs independent of 1 ). The computer selects both combinations 1-2 and 1-3 for the first 2 best tests and compares each remaining test with these 2 combinations to find that combination of 3 tests that effect maximum separation of 10 organisms. Test combinations $1-2-3$ and 1-2-4 effect 33 separations each, but com- 
bination 1-3-4 effects 34 separations and this is selected for the best combination of 3 tests.

By the first analysis it was found the test set was incomplete and organisms could not be separated: 3 from 7, 5 from 7 and 9,6 from 7, and 7 from 9. This means there are 5 separation spaces that cannot be occupied. The total number of spaces is 45 , therefore, the maximum number of spaces that can be filled is 40 .

Table 8. An organism versus organism matrix in which the test number* that results in a separation of 2 organisms is recorded in the appropriate square

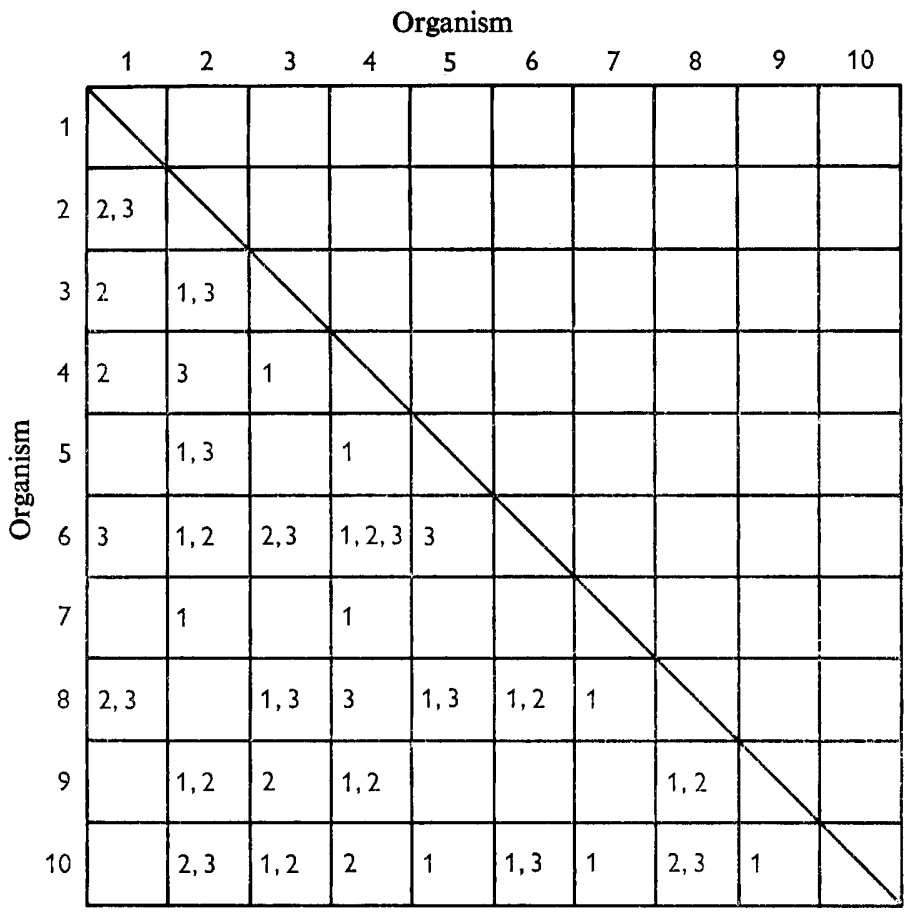

* Test numbers refer to test combinations 1 and 2 or 1 and 3, each combination effecting 29 separations. To determine the number of separations for each combination, the separation spaces (SS) are found by: $S S_{\text {teat }_{1}}+$ (number of times test being compared with 1 occurs independent of 1).

Ten organisms ideally could be separated by a minimum test set of 4 . The number of combinations of 8 tests taken 4 at a time is 70 ,

$$
C_{4}^{8}=\frac{8 \cdot 7 \cdot 6 \cdot 5}{4 !}=70 \text {. }
$$

The computer, however, only makes 5 of these: 1-3-4-5, 1-3-4-6, 1-3-4-7, 1-3-4-8, and 1-3-4-2 which effect the following number of separations, 36, 34, 35, 36, and 36 respectively. Three combinations of 4 tests occupy 36 separation spaces which is the maximum for these tests. Any one of these combinations could be selected as the minimum set. Maximum separation occurs if 40 spaces are occupied; the minimum set occupies 36, and therefore separation is $90 \%$ completed. Four two-state tests have 16 unique combinations $\left(2^{4}=16\right)$. The number of organisms separated into these 16 
possible unique combinations by test combinations $1-3-4-5,1-3-4-8$, and 1-3-4-2 are illustrated in Table 9. Manual analysis of these data indicates that another combination 1-2-4-5 also gives 36 'points of separation' and that the computer did not select this combination.

The largest subgroup for any combination of 4 tests contains 3 organisms. The organisms and the remaining tests in any subgroup that contain 2 or 3 organisms are used as input again and the output is the test or tests that effect separation. This process is continued until separation is complete or until no further separations can be made.

Table 9. Separation of 10 organisms by 3 minimum sets of 4 tests

\begin{tabular}{|c|c|c|c|c|c|c|c|c|c|c|c|c|}
\hline \multirow[b]{2}{*}{ Organisms } & \multicolumn{4}{|c|}{$a$} & \multicolumn{4}{|c|}{$\underset{b}{\operatorname{Minimum}}$ tests } & \multicolumn{4}{|c|}{$c$} \\
\hline & 1 & 3 & 4 & 2 & 1 & 3 & 4 & 5 & 1 & 3 & 4 & $\varepsilon$ \\
\hline 1 & 2 & 0 & 1 & 0 & 2 & 0 & 1 & 2 & 2 & 0 & 1 & c \\
\hline 2 & 0 & 1 & 1 & 1 & 0 & 1 & 1 & 2 & 0 & 1 & 1 & 2 \\
\hline 3 & 1 & 0 & 1 & 1 & 1 & 0 & 1 & 1 & 1 & 0 & 1 & 2 \\
\hline 4 & 0 & 0 & 1 & 1 & 0 & 0 & 1 & 2 & 0 & 0 & 1 & 2 \\
\hline 5 & 1 & 0 & 2 & 2 & 1 & 0 & 2 & 0 & 1 & 0 & 2 & 1 \\
\hline 6 & 1 & 1 & 2 & 0 & 1 & 1 & 2 & 1 & 1 & 1 & 2 & 2 \\
\hline 7 & 1 & 2 & 2 & 2 & 1 & 2 & 2 & 2 & 1 & 2 & 2 & 1 \\
\hline 8 & 0 & 1 & 0 & 1 & 0 & 1 & 0 & 0 & 0 & 1 & 0 & 2 \\
\hline 9 & 1 & 2 & 0 & 0 & 1 & 2 & 0 & 0 & 1 & 2 & 0 & 2 \\
\hline 10 & 0 & 0 & 0 & 0 & 0 & 0 & 0 & 0 & 0 & 0 & 0 & $\mathrm{c}$ \\
\hline
\end{tabular}

Organisms separated into the unique combinations of 4 two-state tests

$\begin{array}{clll} & \text { Organisms } & \text { Organisms } & \text { Organisms } \\ \text { Combination } & a & b & c \\ 1111 & 7 & 6,7 & 6,7 \\ 1110 & 6,7 & 7 & 6 \\ 1101 & 7 & 6,7 & 6,7,9 \\ 1100 & 6,7,9 & 7,9 & 6,9 \\ 1011 & 3,5,7 & 1,3,7 & 3,5,7 \\ 1010 & 1,5,7 & 1,5,7 & 1,3 \\ 1001 & 5,7 & 7 & 5,7,9 \\ 1000 & 5,7,9 & 5,7,9 & 9 \\ 0111 & 2 & 2 & 2 \\ 0110 & \text { None } & 2 & 2 \\ 0101 & 8 & \text { None } & 8 \\ 0100 & \text { None } & 8 & 8 \\ 0011 & 4 & 1,4 & 4 \\ 0010 & 1 & 1,4 & 1,4 \\ 0001 & \text { None } & \text { None } & \text { None } \\ 0000 & 10 & 10 & 10\end{array}$

The programme for the automatic selection of a minimum set of tests agrees, in general, with the manual analysis. Inversions, however, may occur occasionally, but a programme can be devised that will analyse every possible combination of tests.

\section{RESULTS}

Different laboratories may identify the same organism by use of various determinative schemes, that is, different routes to an identification may be used. An attempt has been made, using modified procedures of Gyllenberg $(1963,1964)$ to illustrate a 
generalized method of reducing data of organisms such that the shortest route to an identification will be taken. This entails determining which tests, on the basis of available information, can give maximum separation of organisms in a group. Two examples are used to illustrate these methods.

\section{Selection of 6 tests from 32 tests to separate 36 organisms in the Enterobacteriaceae}

In the first example 36 organisms in the Enterobacteriaceae are used. The data for 32 test results for the organisms are reduced to determine which 6 tests would effect maximum separation of the organisms into 64 possible unique combinations $\left(2^{6}=64\right)$. Data are not available for all organisms and all tests. When this situation is encountered the reaction is considered variable ( $v$ or 2 ) on the assumption that the test must be either 1 or 0 . The confidence level is approximately $80 \%$ but it is emphasized this is biased in favour of indicating more reactions variable.

In general, the classification and nomenclature of Bergey's Manual (1957) or Cowan \& Steel $(1961,1965)$ were used. For this reason, delayed positive reactions are considered negative for the first $24-48 \mathrm{hr}$ in order to differentiate Paracolobactrum species from Escherichia coli, E. freundii, E. intermedium, Aerobacter aerogenes, and $A$. cloacae. The latter organisms, although lactose negative some of the time, are all considered lactose positive. This is illustrated in Table 10, the input for the computer, which is a summary of test results for the 36 organisms. The following references: Bergey's Manual (1957), Cowan (1956), Cowan \& Steel (1961, 1965), Davis, Ewing \& Reaves (1957), Edwards \& Ewing (1964), Kauffmann (1956), Manclark \& Pickett (1961), and Møller (1954), were used to prepare summaries similar to that illustrated in Table 6.

With 36 organisms there are a total of 630 separation spaces $(t(t-1) / 2=36 \cdot 35 /$ $2=630$ ) to be occupied. The 6 first tests selected to effect maximum separation and the number of separations are indicated in Table 11 . Separation is $75.7 \%$ completed by use of these 6 tests $(477 / 630 \times 100=75 \cdot 7 \%)$. Table 12 indicates the subgroups of organisms and which one of the unique combinations each subgroup occupies after use of the minimum test set. Seventeen of the 64 combinations are not occupied, 11 contain 1 organism, 9 contain 2 organisms, 4, 3 organisms, 13, 4 organisms, 3, 5 organisms, 1, 6 organisms, and 6, 7 organisms.

Each of the subgroups with more than 1 organism are separated further using the organisms in the subgroup and the remaining 26 tests as input with an output of the best tests required to effect maximum separation. A minimum set, dependent upon the number of organisms in the subgroup to be separated, is not determined necessarily in these cases. Tests for separation may be selected at this point until all organisms are separated or until further separation is impossible.

\section{Selection of 3 tests from 34 tests to separate 8 species of Pasteurella}

In the second example, the data of Smith \& Thal (1965), used in a numerical taxonomic study of 8 species of the genus Pasteurella, was used for input (Table 13). The output was the minimum test set and the organisms separated into each of the possible combinations of 3 two-state tests (Table 14). The number of separation spaces to be occupied is 28 . 


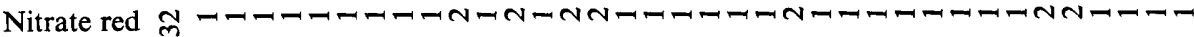
Inositol (gas) m NNNNNTONNNONNNNONNNNNNONNNNNNNNNNNNN

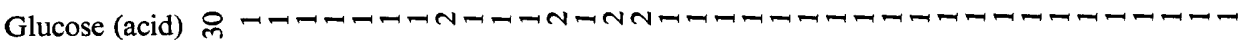

Arginine Aे NNNNNONOONOONOONNNNNNNNOOOOONNNNNNNN

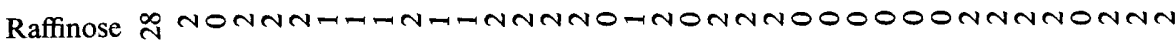
Glutamic acid Nิ moONOONOOOONNNNOOOMNNONNNNNOONNNNN-

Dulcitol ${ }_{2}$ NONNNNNONONNNOOONNON-ONOOOOONNNNNNNN

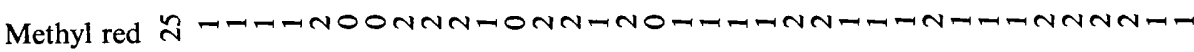

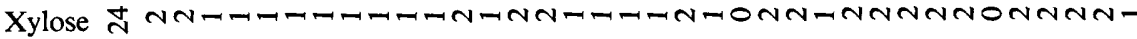

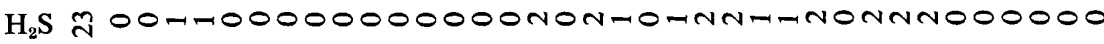

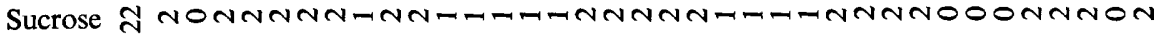
Motility Adonitol \& $0000 N N N O-\pi-N-N N O N N O O N O N O O O M N O O N O O O N O$

Gelatin I OONOONN-0000N000NNNOONNTN00000000000 Rhamnose $\cong$ NNA-IINONNININNININNNOONOONOONNNNNNA

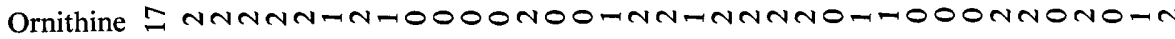

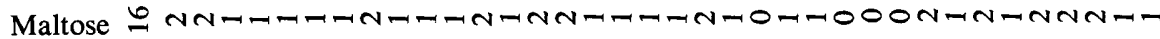
Inositol (acid) 2 OONONTOMNIININNONNOONNNOOONNNNNOOONO

Urease $\sharp$ ONNNNNNNNNOMNAMONNOONONHAT-NOONOOOOOO

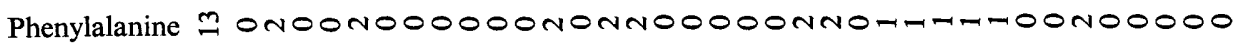

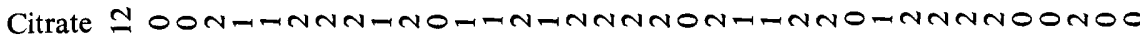
Malonate I ONNONNNOTOFMNNONNNTONNNOOOOOOONO0000 Indole ON-NONNOONOOO-OOONNNNONNTOHIMOONNNNON

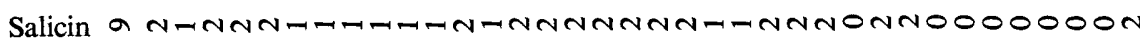
Voges-Pros. 0 ONOO-INNNOZIINNINOONNNONONOOONNNOOO Arabinose $レ$ ーNーーーーーーーーーNーNNNーーーーーONOOONONNNNNNーN

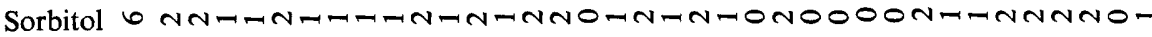

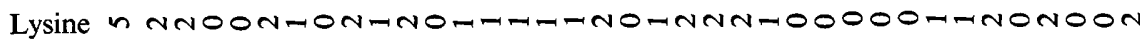
Glucose (gas) $\forall$-ーーーーーーーーNO-ーO-NーーーーーーNNNNNNONNOONOO

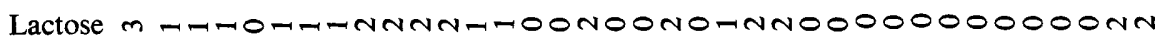

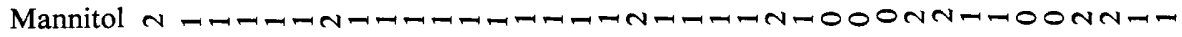

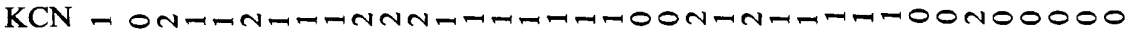

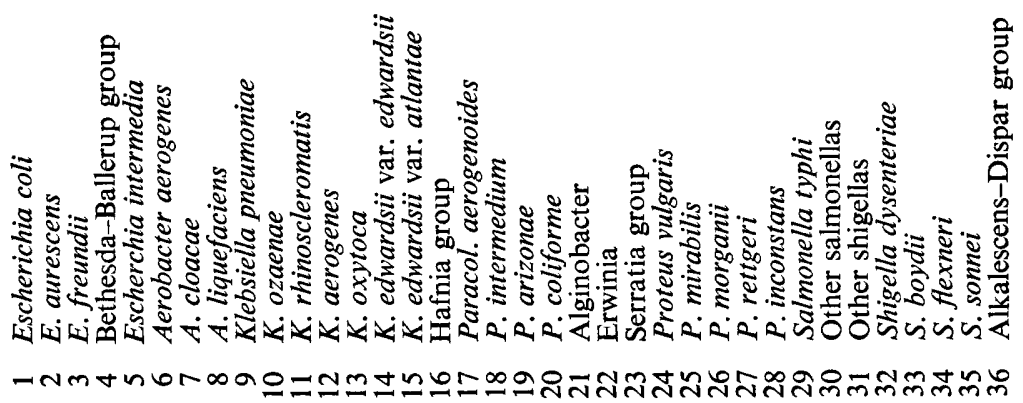


When the $S$ values for each test are calculated, 3 of the 34 tests, 6, 7, and 17, have a maximum $S$ value of 16 . This meets the first part of the idealization previously illustrated (Table 1) that the first 3 tests should have an equal number of 1 and of 0 test results. However, the second part of the idealization is not fulfilled because the alternating sequences of 1's and 0's are not 11110000,11001100 , and 10101010. The $S$ value for these 3 tests is 26 which is not the highest possible value for a combination of 3 of the tests.

Table 11. The first 6 tests and the number of separations effected by successive use of these tests

\begin{tabular}{|c|c|c|c|c|c|c|}
\hline \multicolumn{6}{|c|}{ Tests } & \multirow{2}{*}{$\begin{array}{l}\text { 'Points of } \\
\text { separation }\end{array}$} \\
\hline 1 & 2 & 3 & 4 & 5 & 6 & \\
\hline $\mathrm{KCN}$ & - & - & - & - & - & 180 \\
\hline $\mathrm{KCN}$ & LAC* & - & - & - & - & 293 \\
\hline $\mathrm{KCN}$ & LAC & LD* & - & - & - & 367 \\
\hline $\mathrm{KCN}$ & LAC & LD & $\mathrm{ADON}^{*}$ & - & - & 419 \\
\hline $\mathrm{KCN}$ & LAC & LD & ADON & $\mathrm{H}_{2} \mathrm{~S}$ & - & 452 \\
\hline $\mathrm{KCN}$ & LAC & LD & ADON & $\mathrm{H}_{2} \mathrm{~S}$ & MALT* & 477 \\
\hline
\end{tabular}

* $\mathrm{LAC}=$ lactose, $\mathrm{LD}=$ lysine decarboxylase, $\mathrm{ADON}=$ adonitol, MALT $=$ maltose.

Table 12. Organisms separated into the 64 possible combinations for 6 two-state tests by the minimum set of 6 tests

\begin{tabular}{|c|c|c|c|c|c|}
\hline & Combination & Organisms & & Combination & Organisms \\
\hline 1 & 111111 & 21,23 & 33 & 011111 & 21,23 \\
\hline 2 & 111110 & None & 34 & 011110 & None \\
\hline 3 & 111101 & $5,6,9,10,12,13,23$ & 35 & 011101 & $5,9,10,23$ \\
\hline 4 & 111100 & 12 & 36 & 011100 & None \\
\hline 5 & 111011 & $16,21,23$ & 37 & 011011 & $19,21,23$ \\
\hline 6 & 111010 & 22 & 38 & 011010 & None \\
\hline 7 & 111001 & $2,5,6,8,12,16,23$ & 39 & 011001 & $1,2,5,23,36$ \\
\hline 8 & 111000 & $2,8,12,22$ & 40 & 011000 & 1,2 \\
\hline 9 & 110111 & 21 & 41 & 010111 & 21 \\
\hline 10 & 110110 & None & 42 & 010110 & None \\
\hline 11 & 110101 & $5,7,10,11$ & 43 & 010101 & $5,10,11,35$ \\
\hline 12 & 110100 & None & 44 & 010100 & None \\
\hline 13 & 110011 & 3,21 & 45 & 010011 & 21 \\
\hline 14 & 110010 & 22 & 46 & 010010 & None \\
\hline 15 & 110001 & $2,5,7,8$ & 47 & 010001 & $1,2,5,35,36$ \\
\hline 16 & 110000 & $2,8,22$ & 48 & 010000 & 1,2 \\
\hline 17 & 101111 & 23 & 49 & 001111 & 23 \\
\hline 18 & 101110 & None & 50 & 001110 & None \\
\hline 19 & 101101 & $9,10,14,15,17,23,31$ & 51 & 001101 & $9,10,23,31$ \\
\hline 20 & 101100 & 14,15 & 52 & 001100 & None \\
\hline 21 & 101011 & 16,23 & 53 & 001011 & $19,23,29,30$ \\
\hline 22 & 101010 & 22 & 54 & 001010 & 30 \\
\hline 23 & 101001 & $8,14,15,16,17,23,31$ & 55 & 001001 & $20,23,29,30,31,33,36$ \\
\hline 24 & 101000 & $8,14,15,22$ & 56 & 001000 & $20,30,33$ \\
\hline 25 & 100111 & 18,28 & 57 & 000111 & None \\
\hline 26 & 100110 & 28 & 58 & 000110 & None \\
\hline 27 & 100101 & $10,11,17,18,28,31$ & 59 & 000101 & $10,11,31,35$ \\
\hline 28 & 100100 & 27,28 & 60 & 000100 & None \\
\hline 29 & 100011 & $4,18,24,28$ & 61 & 000011 & None \\
\hline 30 & 100010 & $22,25,26,28$ & 62 & 000010 & None \\
\hline 31 & 100001 & $8,17,18,28,31$ & 63 & 000001 & $20,31,32,33,34,35,36$ \\
\hline 32 & 100000 & $8,22,26,28$ & 64 & 000000 & $20,32,33,34$ \\
\hline
\end{tabular}


Xylose HoOn-Oーーーナm Trehalose m-ONO\#ーーーnNO Sucrose $\mathrm{N}-\pi-7-1006 \mathrm{NN}$ Starch m-OONOOONTn Sorbitol ofO-NーT NoOmma

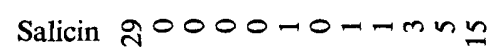
Rhamnose $\stackrel{\text { s }}{0} 000000 \pi-n$ Raffinose సNo0000000No Mannose

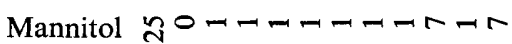
Maltose Inositol กู०0ONNO00060 Glycogen กำ0-0000Th Glycerol तָNONーーーOーオ Galactose ㅇーーーー゚ーーートー Dextrine $\mathrm{A}-\mathrm{N}$ NOーOーVN Cellobiose $\cong 0000-700 \mathrm{~N}$ Arabinose =000ー0ーーーナナに Amygdalin $\because$ NOONTNOOHA Adonitol noo 2 No00- 60 Aesculin $\pm 0000000 \pi$ N Ornithine moO-00-00N decarboxylase -100 Arginine decarboxylase I0000000Noro Lysine decarboxylase $=00000000000$ Litmus 이이음

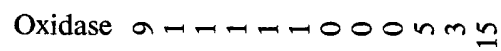
$\mathrm{KCN}$ mONOONOOONO Urease $ヘ ー-000-0 ー+\forall 0$ Methyl red Voges-Proskauer noto $00000-n$ Indole $\forall ー \rightarrow-00000 \mathrm{~min}$ MacConkey mo○০ーーーNーオMN Haemolysis Noror-000min Motility, $22^{\circ}$ - $00000-0-N G N$

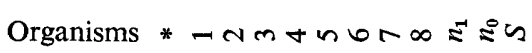


For the first 2 tests 6-4, 6-2, and 6-29 each have an $S$ value of 23. However, for the first 3 tests 2,29, and 7 are selected. This combination results in 27 separations of the required 28 (Table 14). A fourth test, for example, methyl red, used with the first 3 , will separate all the organisms. This type of analysis suggests that input data used in numerical taxonomic studies may be used for constructing identification schemes.

\begin{tabular}{|c|c|c|c|}
\hline \multirow[b]{2}{*}{ Organisms } & \multicolumn{3}{|c|}{ Tests } \\
\hline & $\begin{array}{c}2 \\
\text { Haemolysis }\end{array}$ & $\begin{array}{c}29 \\
\text { Salicin }\end{array}$ & $\begin{array}{c}7 \\
\text { Urease }\end{array}$ \\
\hline 1. P. pneumotropica & 0 & 0 & 1 \\
\hline 2. P. hemolytica var. ureae & 1 & 0 & 1 \\
\hline 3. P. multocida & 0 & 0 & 0 \\
\hline 4. P. hemolytica, type A & 1 & 0 & 0 \\
\hline 5. P. hemolytica, type $\mathrm{T}$ & 1 & 1 & 0 \\
\hline 6. Pasteurella X & 0 & 0 & 1 \\
\hline 7. P. pestis & 0 & 1 & 0 \\
\hline 8. P. pseudotuberculosis & $\mathbf{0}$ & 1 & 1 \\
\hline
\end{tabular}

Separation of organisms into 8 possible combinations of 3 two-state tests

\begin{tabular}{ccl} 
Combination & Number $(n)$ & \multicolumn{1}{c}{ Organisms } \\
111 & 0 & None \\
110 & 1 & $P$. hemolytica, type T \\
101 & 1 & P. hemolytica var. ureae \\
100 & 1 & P. hemolytica, type A \\
011 & 1 & P. peudotuberculosis \\
010 & 1 & $P$. pestis \\
001 & 2 & $P$. pneumotropica Pasteurella X \\
000 & 1 & $P$. multocida
\end{tabular}

\section{DISCUSSION}

With increasing interest in methods of classification in the biological sciences it is important that accurate, rapid, and practical methods be devised for identification of organisms that can keep pace with increasing information content. The method described here involves establishing the number of organisms to be separated. This determines the number of tests required for the minimum set as calculated by Gyllenberg's (1963) $T_{\min }=\log _{2} G$. If each of the tests in the minimum set is considered variable, the number of possible combinations of sequential positive $(+$ or 1$)$ and negative $(-$ or 0$)$ test results is $2^{T_{v}}$ or 2 raised to the power of the number of tests $(T)$ in the minimum set all of which are considered the variable $(v)$. When all possible combinations are constructed this represents the 'logically possible patterns of traits' as described by Birnbaum \& Maxwell (1960). These patterns cover all possibilities of test results for the minimum set for all organisms in the group and do not exclude the use of tests for characters that may be variable for some organisms. This makes it possible to account for known variation in the organisms-or in the sensitivities of different test procedures that may be used to determine the presence or absence of the same trait or character. Once the minimum set is determined on the basis of having the highest number of separations of any combination of tests which the computer is 
programmed to check, a table is constructed of the output which lists all the possible combinations of results for the minimum set and which organisms are placed in each unique combination. This is similar to Table 12 and the bottom of Table 14 which list the possible patterns of combinations for the organisms.

Data for the minimum set of tests for an organism to be separated can be scanned readily on this type of table. An organism may be identified by the minimum set if there is only one organism separated into a unique combination or the organism may be separated into a combination containing more than one organism. In the latter case a second table is scanned which contains another minimum set or the tests selected from those remaining tests required to effect identification of the organisms in the subgroup. If some organisms in a subgroup cannot be separated, a programme has been prepared (R.B.) based upon the relative frequencies of positive and negative results for variable tests which give the most likely answers. In most cases, at present, quantitative data are wanting concerning variable reactions. Notable exceptions are Edwards \& Ewing (1964) and Møller (1954). This part of the programme is analogous to that described by Payne $(1963 a, b)$ for use in the automatic library facility, and Möller (1962) has given consideration to probablistic identification keys. Not all laboratories have access to automatic facilities and laboratories in remote areas may not have communication with such facilities. For this reason up-dated print-out tables should be made available for manual use. The use of these tables is similar to the 'Determinator' described by Cowan \& Steel (1960). In addition, data concerning variable characters may vary geographically and temporarily and the Bayesian approach is suggested (Ledley \& Lusted, 1959).

A limitation of the automatic programme is that all possible combinations of tests are not made. That is, some combination of tests are not made and occasionally these could have higher separation values than those combinations that are selected. However, in Table 10, with 36 organisms and 32 tests, a total of 906,192 combinations of tests would have to be made to find the 32 tests taken 6 at a time that would give the highest number of separations. For this reason a first best test is determined by the separation figure of Gyllenberg (1963) and the tests are arranged in descending order of the $S$ values. Then, each of the remaining tests are used with the first test to determine that combination of 2 tests which give the highest number of separations. On the basis of the highest number of organisms separated by some combination of 2 tests, the tests are rearranged again in descending order of the number of separations. The remaining tests are used with the first 2 to determine the first 3 tests, and this process is continued until the required minimum set is complete.

In a report of a conference on microbial classification, Skerman (1964) introduced the discussion on biochemical tests, and comment was made that standardization of tests may be required for each group of organisms. Discrimination was not made concerning which tests were to be considered for use in identification. In the summary of tests for characters in Table 10 it was not possible always to know if all tests were done by the same procedures. This means there may be an additional bias in this table. For diagnostic purposes some of the tests no doubt could be considered unsatisfactory because of the time required before the test could be read positive or negative.

With the limitation in mind, for example, that the method for determining glucose utilization by Neisseria gonorrhoeae is different than that for $E$. coli it still is possible to reduce data for a large number of organisms when it is known that the same test 
procedure may be used to reveal the presence or absence of a character. A consideration of the environmental conditions necessary for the expression of a character also is useful in identification procedures.

One thing that is needed is more data concerning the characteristics of the bacteria and to reduce this data to determine which tests give the most efficient separations. The diagnostic tables of Cowan \& Steel $(1961,1965)$ help fill this data gap, and Williams (1966) has summarized some of the difficulties of instituting automatic data processing procedures.

This work was supported by funds from the Division of Biology and Medicine, Atomic Energy Commission, U.S.A.

\section{REFERENCES}

Bergey's Manual of Determinative Bacteriology. (1957). 7th ed. Edited by R. S. Breed, E. G. D. Murray, and N. R. Smith, Baltimore: The Williams and Wilkins Co.

Birnbaum, A. \& Maxwell, A. E. (1960). Classification procedures based on Baye's formula. Appl. Statis. 9, 152.

Cowan, S. T. (1956). Taxonomic rank of Enterobacteriaceae 'groups'. J. gen. Microbiol. $15,345$.

Cowan, S. T. \& STEel, K. J. (1960). A devise for the identification of microorganisms. Lancet i, 1172.

Cowan, S. T. \& STEel, K. J. (1961). Diagnostic tables for the common medical bacteria. J. Hyg. Camb. 59, 357.

Cowan, S. T. \& STeel, K. J. (1965). Manual for the Identification of Medical Bacteria. London: Cambridge University Press.

Davis, B. R., EwIng, W. H. \& Reavis, R. W. (1957). The biochemical reactions given by members of the serratia group. Int. Bull. bact. Nomencl. Taxon. 7, 151.

Edwards, P. R. \& EwING, W. H. (1964). Identification of Enterobacteriaceae. Minneapolis: Burgess Publishing Co.

GyllenBERG, H. G. (1963). A general method for deriving determinative schemes for random collections of microbial isolates. Ann. Acad. scient. fenn. Ser. A, IV. Biologica, no. 69, 1.

GyllenberG, H. G. (1964). An approach to numerical description of microbial populations. Ann. Acad. Scient. fenn. Ser. A, IV. Biologica, no. 81, 2.

Kauffmann, F. (1956). A simplified biochemical table of Enterobacteriaceae. Acta path. microbiol. scand. 39, 103.

LEDley, R. S. \& LuSted, L. B. (1959). The use of electronic computers to aid in medical diagnosis. Proc. I.R.E. 47, 1970.

LySENKo, O. (1959). The use of models in bacterial classification. J. gen. Microbiol. $20,284$.

MANClaRk, C. R. \& PicketT, M. J. (1961). Diagnostic bacteriological screening procedures. Lab. World 12, 446.

MöLlER, F. (1962). Quantitative methods in the systematics of Actinomycetales. IV. The theory and application of a probabilistic identification key. G. Microbiol. 10, 29.

Møller, V. (1954). Distribution of amino acid decarboxylases in Enterobacteriaceae. Acta path. microbiol. scand. 35, 259.

PAYNe, L. C. $(1963 a)$. Towards medical automation. World Med. Electron. 2, 6.

Payne, L. C. $(1963 b)$. New computing techniques in medicine. Proc. Roy. Soc. Med. 56, 560.

Skerman, V. B. D. (1964). Cited in: Microbial classification. Nature, Lond. 204, 425.

SMITH, J. E. \& Thal, E. (1965). A taxonomic study of the genus Pasteurella using a numerical technique. Acta path. microbiol. scand. 64, 213.

Williams, D. (1966). Data processing varies with laboratory problems. Lab. Management 4, 37. 